\title{
EXPERIÊNCIAS COM ENSINO E FORMAÇÃO CONTINUADA DE PROFESSORES DE HISTÓRIA EM PARINTINS (AMAZONAS)
}

\author{
DiEGO OMAR DA SILVEIRA* \\ CLARICE BIANCHEZZI ${ }^{* *}$
}

\begin{abstract}
Resumo: o artigo discute, brevemente, o perfil, a formação e as perspectivas de professores de História da rede estadual de ensino em Parintins, cidade localizada na região do médio-baixo Amazonas, na divisa dos estados do Amazonas e Pará. Nossas reflexões estão articuladas em torno das experiências desenvolvidas ao longo de pouco mais de um ano (2014-2015) em que a Universidade do Estado do Amazonas, por meio de convênio com a Secretaria de Estado de Educação, ofereceu a esses docentes um curso de pós-graduação lato-sensu em Metodologias do Ensino de História e investiga as formas pelas quais essa formação influenciou nas escolhas posteriores destes professores, marcando inclusive o retorno de vários deles à Universidade, em cursos de mestrado e doutorado, e a contribuição da mesma no desenvolvimento dos conteúdos históricos na educação básica.
\end{abstract}

Palavras-chave: Professores de História, perfil, formação, perspectivas, Parintins.

\section{Experiences with teaching and continued training of history teachers in Parintins (Amazonas)}

\begin{abstract}
This paper briefly discusses the profiles, academic backgrounds and perspectives of History teachers from the state schools in Parintins, a town located in the midlower region of the Amazon river, at the border between the states of Amazonas and Pará. Our considerations derive from experiences which took place along just over a year's time (2014-2015) in which the Universidade do Estado do Amazonas offered the teaching staff a lato sensu postgraduate course in History Teaching Methodologies through a partnership with the State Department of Education. We investigated the ways through which this qualification has influenced subsequent teaching choices made by those teachers, also highlighting the return of many of them to the University, in Master's and Doctoral courses, as well as its contribution to the way historical contents are approached in basic education.
\end{abstract}

Keywords: History teachers, profile, academic background, perspectives, Parintins.

\footnotetext{
* Graduado e mestre em História pela Universidade Federal de Ouro Preto (UFOP). Doutorando em Antropologia Social pela Universidade Federal do Amazonas (UFAM). Professor assistente do curso de História do Centro de Estudos Superiores de Parintins da Universidade do Estado do Amazonas (UEA). E-mail: diegomarhistoria@yahoo.com.br

** Graduada em História na Universidade do Estado de Santa Catarina (UDESC) e mestre em Educação na Universidade Federal de Santa Catarina (UFSC). Doutoranda em Antropologia (área de concentração: Arqueologia) na Universidade Federal do Pará (UFPA). Professora assistente do curso de História do Centro de Estudos Superiores de Parintins da Universidade do Estado do Amazonas (UEA). Foi coordenadora da Especialização em Ensino de História entre 2014 e 2015. E-mail: cbianchezzi@yahoo.com.br
} 
Os recentes debates em torno da promulgação na Base Nacional Comum Curricular (BNCC) tendem a reascender nos meios acadêmicos e entre os docentes das redes públicas de ensino no Brasil um conjunto de questões ligadas não apenas ao currículo do Ensino Básico, mas também às condições em que ocorrem o trabalho docente, à formação inicial (e continuada) dos professores, aos materiais e livros didáticos, entre tantas outras questões. Voltam igualmente à cena as dificuldades de estabelecer parâmetros comuns em um país tão diverso e desigual e, acima de tudo, a necessidade de compreender mais a fundo como diferentes propostas de ensino emergem em cada contexto, produzindo, assim, efeitos locais, difíceis de mensurar, mas imprescindíveis para reforçar o papel social da História em tempos disruptivos, nos quais parecemos estar presos aos "entre-lugares" do presente (Silva e Guimarães, 2012).

Do ponto de vista disciplinar, os conteúdos ministrados nas escolas tornam-se, hoje, ao mesmo tempo ameaçados e conclamados a assumir um papel decisivo na arena política e social. Uma vez contestada em sua utilidade da História para o mercado de trabalho e para a produção massiva de jovens diplomados no Ensino Superior, a proposta é de, mais uma vez, dirimir a disciplina em um conjunto amorfo de "competências específicas de Ciências Humanas e Sociais Aplicadas", como consta, por exemplo, na proposta do Ministério da Educação do Governo Temer para o que se chama de “Novo Ensino Médio". Embora haja evidente contradição entre apontá-la como um dos pilares para "estimular a autonomia de pensamento e a capacidade de reconhecer que os indivíduos agem de acordo com a época e o lugar nos quais vivem" (Brasil, 2017, p. 350) no Ensino Básico para, na sequência, eliminá-la da formação secundária, tais questões têm sido permanentemente deixadas de lado pela burocracia estatal, que aliás tem paulatinamente anulado também as vozes das associações de historiadores e educadores (como a ANPUH e a ANDEd) nos processos decisórios. Esse movimento rompe uma articulação entre as Universidades (com seus cursos de formação inicial e continuada) e o Governo Federal que, ainda com alguns descompassos, vinha se consolidando desde o final da ditadura civil-militar, de modo especial no pós-1988, com a promulgação da Constituição e Lei de Diretrizes e Bases (1996).

Mais do que nunca, porém, historiadores e professores de História nos vemos conclamados a atuar na construção de sociedades politicamente mais democráticas e socialmente mais justas, sob a consciência de que o "caráter temporalmente denso do 
presente" deve servir para que o tomemos "não como uma dimensão fechada em si mesma, mas como o resultado da própria história viva com a qual sempre nos relacionamos". Nessa perspectiva, assinalada por Valdei Lopes de Araújo (2012, p. 68), "se toda história é uma história do presente, todo presente, inclusive nos interesses que pode articular, é o resultado de uma história da qual não pode separar, senão apenas formalmente, suas dimensões pretéritas e futuras". Para os que testemunharam, em fins do século XX, as articulações de um currículo de História em torno das noções de cidadania e participação de indivíduos e coletividades cada vez mais amplas (cf. Guimarães, 2003) parecia improvável que voltássemos a ver algum dia professores constrangidos em sua liberdade de ensinar, sob a acusação de fazerem doutrinação ou subversão das lógicas familiares e em um ambiente no qual parte considerável da população é simpática a projetos que propõem uma "escola sem partido", como sustentáculo dos valores morais e religiosos tradicionais, inclusive do culto aos heróis da pátria.

Compreendemos, assim, que nosso papel deve ser o de analisar criticamente os descaminhos da História que ensinamos e seu futuro, seja na universidade ou nas escolas de Ensino Básico. Isso passa necessariamente por considerar a nossa disciplina como "fundamentalmente educativa, formativa, emancipatória e libertadora (...) que tem como papel central a formação da consciência histórica dos homens, possibilitando a construção de identidades coletivas, a elucidação do vivido, a intervenção social e praxes individuais e coletivas" e também, segundo Selva Guimarães (2003, p. 89) pela consciência de que o debate sobre o significado de ensinar história processa-se, sempre, no interior de lutas políticas e culturais", perpassadas pelas lógicas e conflitos que "envolvem tanto produção quanto a difusão do conhecimento, apontando limites, desejos e necessidades historicamente construídas".

Partindo de um recorte bastante circunscrito, buscamos nesse artigo nos indagar - à luz dessas questões - sobre o que temos feito (?), o que, por sua vez se desdobra em uma (auto)avaliação de nossas atuações no Centro de Estudos Superiores de Parintins da Universidade do Estado do Amazonas. Sendo assim, o que os leitores encontrarão aqui é uma leitura, ainda que provisória - porque sujeita a redirecionamentos, acerca do perfil, da formação e das perspectivas de professores de História da rede estadual de ensino em Parintins, com os quais travamos contato mais estreito ao longo de 2014 e 2015, durante um curso de pós-graduação lato-sensu em Metodologi- 
as do Ensino de História, oferecido pela UEA em parceria com Secretaria de Estado de Educação (SEDUC). Buscamos indicar as percepções desses sujeitos sobre esse esforço de formação continuada e as formas pelas quais essa especialização influenciou nas escolhas posteriores destes professores, já que alguns ingressaram logo na sequência em cursos de mestrado (e posteriormente doutorado). Na medida do possível, apontamos para a contribuição da mesma para que novos/outros conteúdos e/ou abordagens permeassem aquilo que é ministrado em suas salas de aula, na Educação Básica.

\section{Rede estadual de ensino: Amazonas e Parintins}

Considerando um conjunto de novos estudos sobre as didáticas e práticas de ensino, uma proposta pedagógica não pode ser compreendida quando desarticulada de seu contexto mais amplo. E embora essa seja uma realidade de todas as disciplinas - "inseridas em uma escola (pessoal docente e corpo técnico, corpo discente, condições materiais de funcionamento, interdisciplinaridade, projeto pedagógico)", e como propõe Marcos Silva (2013, p. 13) "numa sociedade (mais que consumidores: cidadãos com direitos, deveres e poderes, demandas de Estado e grupos e sociais), [e] num mundo (limites da natureza, disparidades econômicas, conflitos étnicos e nacionais, inovações culturais tradições)" - é uma questão que merece atenção especial no campo da História. Isso porque, para além daquilo que prescrevem os currículos oficiais e do que consta nos materiais didáticos, há em História uma ampla discussão sobre o que deve ser ensinado, de qual perspectiva e por meio de quais linguagens e estratégias (?). Um mínimo de consenso gira em torno de que a realidade cotidiana - de educadores e educandos - são decisivos nos processos de construção coletiva de conhecimento, devendo portanto guiar uma parte significativa dos problemas a serem investigados e analisados, de que os conceitos ganham sempre outros sentidos quando ancorados nas vivências dos estudantes e de que a escola deve ser encarada como um espaço de "reconstrução da experiência num processo de socialização com vistas à emancipação" (Monteiro, 2000, p. 39).

Para tanto nos parece necessária aqui uma breve descrição do local/estado em que transcorre a experiência narrada, não com a finalidade de exaurir, com dados oficiais, a leitura dessa realidade. Mas antes, e pelo contrário, com o objetivo de fornecer ao leitor algumas chaves para compreender, ainda que parcialmente, os aspectos mais centrais dessa realidade educacional. 
Como é sabido, o estado do Amazonas é a maior das unidades federativas brasileiras em extensão territorial, com 1.559.146,876 km². Ali está também uma imensa bacia hidrográfica, responsável por aproximadamente um quinto do fluxo fluvial de todo o mundo, dentro de uma das maiores florestas tropicais do planeta. Isso impacta, naturalmente, os modos vida dos aproximadamente quatro milhões de amazonenses, em suas formas de lidar com a natureza e o espaço, sua cultura material e intelectual, suas experiências educacionais (escolares ou cotidianas). Dadas as distâncias, a oscilação do volume de água nos rios, a existência de diversas reservas indígenas e agroflorestais, coexistem nas áreas urbanas e rurais do Amazonas diferentes modelos de escola, distintos calendários escolares e várias propostas pedagógicas - que se somam e se sobrepõem - dificultando até mesmo mensurar os resultados pelos critérios adotados há algumas décadas por governos e agências internacionais.

De acordo com os dados consolidados das matrículas que constam nas Sinopses Estatísticas da Educação Básica de 2017 do Instituto Nacional de Estudos e Pesquisas Educacionais Anísio Teixeira (INEP), no Amazonas existem 5.493 instituições de ensino (básico e superior): 16 da rede federal, 751 da rede estadual, 4.398 da rede municipal e 328 da rede privada. ${ }^{1}$ Tamanha complexidade seria difícil de descrever no limite deste artigo, além de fugir dos nossos propósitos mais imediatos. Nosso interesse, por ora, é situar nesse quadro mais amplo o município de Parintins: segunda maior cidade do estado, com população estimada em 113.168 habitantes e uma rede escolar que comporta, segundo o último Censo Escolar, 176 instituições de ensino, sendo: 1 federal, 23 estaduais, 146 municipais e 06 privadas. $^{2}$ No último ano foram 20.309 matrículas no Ensino Fundamental e 6.776 no Ensino Médio; 1.041 docentes atuando no Ensino Fundamental e 307 no Ensino Médio. ${ }^{3}$ Os dados sobre o número de professores por lotados em cada disciplina não se encontram disponibilizados pela Secretaria de Educação do Estado (SEDUC), órgão que embora tenha sido consultado, não nos forneceu os dados solicitados.

A distribuição das vagas e as condições de oferta dessas modalidades de ensino

\footnotetext{
${ }^{1}$ Sinopses Estatísticas da Educação Básica de 2017. Disponível em http://portal.inep.gov.br/web/guest/ sinopses-estatisticas-da-educacao-basica. Consulta em 05.06.2018.

2 Dados do Censo Escolar (Matrícula inicial - Mapa de Escolas). Disponível em: https://inepdata.inep.gov.br/analytics/saw.dll?Dashboard. Consulta em 05.06.2018.

3 Dados do IBGE. Disponíveis em https://cidades.ibge.gov.br/brasil/am/parintins/panorama. Consulta em 12.06.2018.
} 
variam enormemente, não apenas dentro da cidade - aonde impactam as condições físicas das instalações escolares e o acesso a recursos didáticos equipamentos (quando se considera a relação centro-periferia), mas sobretudo entre a área urbana e as comunidades ribeirinhas, nas quais trabalhos monográficos ou sínteses já mais consolidadas apontam a permanência de precárias condições estruturais, de classes multisseriadas e de professores atuando com pouca ou nenhuma qualificação profissional (cf. Cavalcante e Weigel, 2002). Ainda que lentamente, essa realidade vem se alterando nos últimos anos pela atuação conjunta dos poderes públicos que encaparam processos de interiorização das universidades públicas ${ }^{4}$ e de programas para assegurar formação inicial e continuada para professores com evidentes dificuldades de acesso ao Ensino Superior, como o PRORURAL, o PROFORMAR e, mais recentemente, o PARFOR. ${ }^{5}$

No que diz respeito especificamente à História, a oferta da licenciatura pelo CESP/UEA tem qualificado anualmente, desde 2002, novos professores para o exercício da docência nas escolas locais. No acompanhamento aos egressos temos notado que boa parte deles tem assumido encargos didáticos na rede estadual, sobretudo nos anos finais do Ensino Fundamental e no Ensino Médio, acessando a carreira por meio de designação ou concurso público. Tendo em vista a configuração urbana de uma cidade do interior, as relações entre a Universidade e as escolas são relativamente próximas e constantes, via, por exemplo, a realização de estágio supervisionado dos alunos da licenciatura ou da implementação de subprojetos do Programa Institucional de Bolsas de Iniciação à Docência (PIBID) em colégios da rede pública de ensino. Nosso contato com professores lotados em escolas "do interior", fora do núcleo urbano, se deu durante a vigência de uma turma de segunda licenciatura em História (PARFOR), entre 2013 e 2015.

Por vezes, surgem ainda parcerias provenientes da realização de eventos de caráter acadêmico-científico, de projetos de extensão da Universidade do Estado do A-

\footnotetext{
${ }^{4}$ Atualmente Parintins conta com campus da Universidade do Estado do Amazonas, da Universidade Federal do Amazonas e do Instituto Federal de Educação, Ciência e Tecnologia.

${ }^{5}$ Sobre o PRORURAL, Cavalcante e Weigel (2002) mencionam a meta de formar 4.285 professores. Para o PROFORMAR, Caio Henrique Faustino da Silva e André Luis Nunes Zogahib (2015) falam em 16.000 docentes da rede pública beneficiados. Os dados oficiais do PARFOR são de 2.315 turmas concluídas até 2017, com 44.843 formados e 588 turmas em andamento em 2018, com aproximadamente 22.550 estudantes.
} 
mazonas ou do desenvolvimento de projetos financiados pelas agências de fomento, em espacial pela Fundação de Amparo à Pesquisa do Estado do Amazonas (FAPEAM), como nos casos do Programa Ciência na Escola (PCE) e do Programa de Popularização da Ciência (POP). Uma política efetiva de verticalização dos cursos (com oferecimento de pós-graduação lato e stricto sensu) nunca foi, entretanto, privilegiada nem amplamente discutida na instituição. ${ }^{6}$ Surgiram, via de regra, em função de convênios assinados pela gestão superior para atender a diferentes órgãos do Estado com disponibilidade financeira e orçamentária de aportar recursos nas diferentes escolas ou centros da UEA.

Nesse sentido, entre 2013 e 2015 vários cursos de especialização em Metodologias do Ensino foram oferecidos por meio de um convênio entre a Secretaria de Estado de Educação e a UEA, visando capacitar os professores (concursados) para o exercício docente de acordo com as metodologias e práticas de ensino mais atualizadas, de modo que se pudesse também manter vivos os laços entre os campus da UEA e as escolas de Ensino Básico. Os recursos conveniados com a Secretaria de Educação subsidiaram, de acordo com as fontes oficiais do Estado, a remuneração de docentes, a aquisição de equipamentos para os colegiados dos cursos ofertados e a melhoria dos acervos bibliográficos da Universidade - o que atende tanto às licenciaturas quanto às necessidades de atualização dos referenciais com quais os professores trabalham no planejamento e execução de suas aulas.

\section{Contornando dificuldades: o desenho de um curso de especialização}

O projeto inicial para a área de História foi elaborado no Centro de Estudos Superiores de Tefé e, com pequenas adequações, foi implantado em Parintins a partir de março de 2014. O conjunto de atividades propostas somavam, atendendo às exigências legais, 360 h/a, distribuídas em 12 disciplinas presenciais de 30h/a (conforme quadro abaixo), ministradas aos sábados, às quais se somava a elaboração de um Trabalho de Conclusão de Curso em formato de artigo acadêmico.

\section{Quadro de disciplinas (Carga Horária e Docentes)}

\footnotetext{
${ }^{6}$ Dados sobre os cursos de Graduação e Pós-Graduação ofertados nos últimos anos podem ser encontrados no Plano de Desenvolvimento Institucional (PDI) da Universidade do Estado do Amazonas: 2017-2021. Disponível em http://www.pdi.uea.edu.br/.
} 


\begin{tabular}{|l|l|l|}
\hline Disciplinas & CH & Docentes \\
\hline História Antiga e Medieval para o Ensino Básico & $30 \mathrm{~h} / \mathrm{a}$ & Ms. Noélio Martins (IFAM) \\
\hline Metodologias do Ensino de História & $30 \mathrm{~h} / \mathrm{a}$ & Ms. Mary Tânia dos Santos Carvalho (UEA) \\
\hline Metodologia do Projeto de Pesquisa em História & $30 \mathrm{~h} / \mathrm{a}$ & Ms. João Marinho da Rocha (UEA) \\
\hline História e Ensino de História & $30 \mathrm{~h} / \mathrm{a}$ & Ms. Arcângelo da Silva Ferreira (UEA) \\
\hline $\begin{array}{l}\text { Tópicos especiais em História Moderna e Con- } \\
\text { temporânea }\end{array}$ & $30 \mathrm{~h} / \mathrm{a}$ & Ms. Diego Omar da Silveira (UEA) \\
\hline História Indígena e Indigenismo & $30 \mathrm{~h} / \mathrm{a}$ & Esp. Jackson Barros \\
\hline Didática do Ensino de História & $30 \mathrm{~h} / \mathrm{a}$ & Ms. Mary Tânia dos Santos Carvalho (UEA) \\
\hline Tópicos especiais em Historiografia Brasileira & $30 \mathrm{~h} / \mathrm{a}$ & Ms. Diego Omar da Silveira (UEA) \\
\hline $\begin{array}{l}\text { Introdução à História da África e dos Afro- } \\
\text { brasileiros }\end{array}$ & $30 \mathrm{~h} / \mathrm{a}$ & Dr. Júlio Claudio da Silva (UEA) \\
\hline $\begin{array}{l}\text { Ensino de História, Novas Linguagens e Novas } \\
\text { Tecnologias }\end{array}$ & $30 \mathrm{~h} / \mathrm{a}$ & Ms. Carlos Magno de Camargo (UFAM) \\
\hline Estruturas curriculares e interdisciplinaridade & $30 \mathrm{~h} / \mathrm{a}$ & Dra. Elizandra Garcia da Silva (UFAM) \\
\hline Tópicos especiais em História da Amazônia & $30 \mathrm{~h} / \mathrm{a}$ & Ms. Arcângelo da Silva Ferreira (UEA) \\
\hline
\end{tabular}

O recrutamento dos docentes se deu por meio de candidaturas junto à coordenação, sendo privilegiados os professores da UEA, mas podendo ser admitidos docentes de outras Instituições de Ensino Superior públicas ou privadas, cujo título fosse no mínimo especialista (o que permitiu a oferta da espacialização pelos professores nomeados acima). Já os discentes da especialização foram inscritos voluntariamente, atendendo a levantamento prévio da Secretaria de Estado de Educação dos profissionais concursados e no exercício regular de suas funções. Esse foi, talvez, o maior obstáculo, tendo em vista o evidente déficit de vagas nos últimos concursos públicos e o número, consequentemente, reduzido de professores considerados aptos a cursar a especialização. Embora tenhamos argumentado em favor da otimização dos recursos públicos e do oferecimento de vagas a um conjunto amplo de interessados, dos 48 inscritos apenas 24 homologados, 14 matriculados e apenas 07 concluíram a especialização.

Desde já cumpre salientar o quanto a realidade burocratizada da gestão dos sistemas de ensino contrasta, em certo sentido pelo menos, com o desejo de consolidar os "conhecimentos teórico-práticos" disponíveis aos professores da rede pública, ampliando suas possibilidades de manejar novos conhecimentos e técnicas em sua atuação como docente. Na justificativa do projeto pedagógico do curso tínhamos, por exemplo, uma vinculação entre a "renovação por que passa o conhecimento histórico" e a necessidade de (re)situar a Amazônia no conjunto dos saberes disponíveis em sala de aula, fortalecendo os vínculos entre ensino e pesquisa, colocando acento no caráter criador da atividade docente e vinculando o que é ensinado e aprendido sobre história 
com a possibilidade de "viver melhor".

Nessa esteira, os objetivos do curso foram: capacitar professores da rede pública do Ensino Básico, renovando, aprofundando e atualizando os conhecimentos adquiridos na graduação, e atendendo as necessidades de formação docente em metodologia do ensino e pesquisa no campo da história; e subsidiariamente:

a) Capacitar o profissional em distintas concepções teórico-metodológicas para o ensino de uma História crítica-reflexiva; b) Qualificar para a pesquisa histórica e a produção de monografias, assim como para a construção do conhecimento histórico escolar; c) Conscientizar o profissional de História de que através de novos métodos de ensino-aprendizagem, é possível intervir na realidade concreta da comunidade escolar e da sociedade mais ampla.

Havia também no projeto a descrição das "competências e habilidades" que se almejava construir/ reforçar ao longo da especialização:

a) Domínio sobre as linhas gerais do processo histórico em suas várias dimensões; b) Conhecimento das principais vertentes teóricas que orientam as análises históricas; c) Articulação entre informação e teoria de forma crítica nas atividades de pesquisa e magistério; d) Respeito às diferenças; e) Novas abordagens didáticas e metodologias de ensino-aprendizagem focadas no conhecimento histórico para o Ensino Básico; f) Reflexão crítica sobre o ensino de história na escola e na comunidade; g) Desenvolvimento de práticas modificadoras que permitam a melhoria qualitativa do ensino e da qualidade de vida da sociedade.

Para tanto, a concepção do programa se deu em dois "eixos estruturantes". O primeiro, mais voltado para uma atualização historiográfica, com discussões focadas em conteúdos que correspondem aos temas mais abordados em sala de aula. As disciplinas desse eixo visavam reforçar ou aprofundar os conhecimentos adquiridos pelos professores durante as suas formações iniciais (como nos casos de "Tópicos especiais em História Moderna e Contemporânea" e "Tópicos especiais em Historiografia Brasileira") ou cobrir eventuais lacunas das licenciaturas, tendo em vista as transformações na legislação educacional brasileira e as demandas sociais que trouxeram para o âmbito do currículo a necessidade de discutir, por exemplo, a "História indígena e do indigenismo" e a "História da África e dos afrobrasileiros". Também aqui se buscava dar nova centralidade aos estudos amazônicos, com destaque para os avanços recentes da historiografia local, cada vez mais plural e atenta às diversidades internas ao que se convencionou como Amazônia. 
O segundo eixo foi pensado para atender mais às demandas da reflexão sobre ensino e a aprendizagem da História. Concentrou, por isso, discussões de caráter didático-pedagógico, colocando em relevo: as "Estruturas curriculares e interdisciplinaridade", as relações entre "História e Ensino de História", a "Didática do Ensino de História" e as "Metodologias do Ensino de História". Duas outras disciplinas atentavam para questões mais específicas, embora não menos importantes. "História Antiga e Medieval para o Ensino Básico" buscava contornar a dificuldade de muitos docentes em tratar de conteúdos tão distantes da nossa realidade, abordados de maneira esquemática nos livros didáticos e demasiadamente estereotipado nas representações da indústria cultural. Daí que a ementa contemplasse inclusive o "uso de imagens e filmes como referências para o estudo desse período. Já “Ensino de História, novas linguagens e novas tecnologias" surgia para responder às questões mais atuais no campo da produção e da divulgação do conhecimento histórico, em um contexto de acesso facilitado às ferramentas digitais e midiáticas no qual tanto a pesquisa quanto o ensino se tornam mais interdisciplinares, dinâmicos e flexíveis (cf. Guimarães, 2012, p. 259ss; ver também Pinsk, 2013.).

Trabalhos de Conclusão de Curso

\begin{tabular}{|l|l|l|}
\hline Aluno & Tema & Orientador \\
\hline $\begin{array}{l}\text { Cristiana Andrade } \\
\text { Butel }\end{array}$ & $\begin{array}{l}\text { Do Japão a Amazônia: história e memória da colônia } \\
\text { japonesa na Vila Amazônia }\end{array}$ & $\begin{array}{l}\text { Ms./ Mary Tânia dos } \\
\text { Santos Carvalho (UEA) }\end{array}$ \\
\hline $\begin{array}{l}\text { Eliomar Cardoso } \\
\text { Novo }\end{array}$ & $\begin{array}{l}\text { Diversidade religiosa no ensino de História: reflexões } \\
\text { sobre a prática docente }\end{array}$ & $\begin{array}{l}\text { Ms. Diego Omar da } \\
\text { Silveira (UEA) }\end{array}$ \\
\hline $\begin{array}{l}\text { Gilciandro Prestes } \\
\text { de Andrade }\end{array}$ & $\begin{array}{l}\text { História e Memória: da invasão a fundação do bairro } \\
\text { Paulo Correia em Parintins }\end{array}$ & $\begin{array}{l}\text { Dr. Júlio Claudio } \\
\text { da Silva (UEA) }\end{array}$ \\
\hline $\begin{array}{l}\text { Jessica Dayse } \\
\text { Matos Gomes }\end{array}$ & $\begin{array}{l}\text { Cinema e ensino de História: o uso de filmes como ins- } \\
\text { trumento didático em uma escola em Parintins }\end{array}$ & $\begin{array}{l}\text { Ms. Diego Omar da } \\
\text { Silveira (UEA) }\end{array}$ \\
\hline $\begin{array}{l}\text { Klinger Tavares } \\
\text { Farias }\end{array}$ & $\begin{array}{l}\text { Ditadura militar e ensino de História: reflexões e apon- } \\
\text { tamentos teórico-práticos }\end{array}$ & $\begin{array}{l}\text { Ms. Diego Omar da } \\
\text { Silveira (UEA) }\end{array}$ \\
\hline $\begin{array}{l}\text { Lucineli de Souza } \\
\text { Menezes }\end{array}$ & $\begin{array}{l}\text { A utilização do livro didático de História: práticas e possi- } \\
\text { bilidades no 6o ano fundamental em três escolas estadu- } \\
\text { ais de Parintins }\end{array}$ & $\begin{array}{l}\text { Ms. Noélio Martins } \\
\text { (IFAM) }\end{array}$ \\
\hline $\begin{array}{l}\text { Naia Maria Guer- } \\
\text { reiro Dias }\end{array}$ & $\begin{array}{l}\text { Sítio arqueológico da região de Valéria/AM: turismo e } \\
\text { educação patrimonial em contexto rural }\end{array}$ & $\begin{array}{l}\text { Ms. Mary Tânia dos } \\
\text { Santos Carvalho (UEA) }\end{array}$ \\
\hline
\end{tabular}

Por fim, o trabalho de conclusão de curso, elaborado na forma de artigo científico, visava possibilitar que os passos da construção de uma pesquisa fossem retomados, em alguns casos mobilizando os conteúdos das disciplinas e em outros formatando objetos que se ligavam de alguma forma à trajetória (pessoal e/ou profissional) 
desses professores-pesquisadores. Como se pode ver na tabela acima, os temas foram bastante distintos e atendem desde questões mais globais até aspectos da história local, variando igualmente as fontes, os recortes e as metodologia empregados. Todos tiveram que passar, em algum limite, por questões ligadas ao ensino, sem necessariamente produzir um material (para)didático. Uma vez finalizados, os trabalhos foram apresentados à comunidade acadêmica na forma de banners e, recentemente, os que permaneciam inéditos (ou seja, não haviam sido publicados em periódicos) foram adaptados, em parceria com os orientadores, e serão publicados em formato de livro (coletânea, no prelo) da editora da Universidade do Estado do Amazonas.

\section{Perfil dos que cursaram a especialização}

Para compreender melhor a oferta e a avaliação do curso, acreditamos que vaIha a pena traçar aqui um breve perfil dos concluintes. ${ }^{7} \mathrm{~A}$ faixa etária prevalente é de 31 a 40 anos e mais de $70 \%$ são mulheres. A identificação de cor da pele, de acordo com as categorias do censo demográfico, foi majoritariamente parda (aproximadamente $60 \%)$, havendo apenas $1(14,3 \%)$ que se identifica como indígena. A composição familiar é bastante heterogênea, com solteiros e casados ou em união estável em quase iguais proporções. Entre os mais jovens é mais comum "morar sozinho", enquanto os que vivem com os pais ou com cônjuges indicaram possuir dependentes. Considerando os valores atuais do salário mínimo (de $\mathrm{R} \$ 937,00$ ) a faixa de renda renda familiar mais indicada foi de 3 a 5 salários.

Sobre a formação, todos cursaram o Ensino Básico completo em escolas da rede pública e se formaram no Ensino Superior na Universidade Federal do Amazonas (UFAM) ou na Universidade do Estado do Amazonas (UEA). 85,8\% possui formação inicial em História e apenas uma professora cursou a licenciatura em Filosofia. Outra destacou ter se formado também em Normal Superior. A maioria não chegou a participar durante a graduação de nenhum programa remunerado na universidade (com bolsas da UEA, FAPEAM, etc.) nem foi beneficiária de nenhum programa de cotas ou de ações afirmativas. Quase a metade já participou do Programa Ciência na Escola

\footnotetext{
${ }^{7}$ Os dados foram obtidos com base em formulário elaborado pelos autores deste artigo especificamente para esse fim e enviado por e-mail aos que cursaram a especialização em junho de 2018. Os valores em percentual são aproximados.
} 
(PCE), da Fundação de Amparo à Pesquisa do Amazonas, que apoia a pesquisa e a produção de recursos didáticos por meio de bolsas a professores e estudantes de Ensino Médio. Cerca de $57 \%$ já possuíam pós-graduação lato-sensu antes de cursar a especialização em Metodologias do Ensino de História. As áreas e as instituições que ofertaram essas formações variam, dada a oferta esporádica de especializações nas universidades públicas presentes em Parintins e a presença na cidade de várias pequenas faculdades particulares, com oferta de cursos modulares ou a distância e com preços relativamente acessíveis.

Após concluírem a especialização, cinco (dos sete concluintes) ingressaram no mestrado, a maioria em função da política de interiorização da pós-graduação da UFAM, que passou a ofertar nos interiores do estado turmas de mestrado e doutorado do Programa de Pós-Graduação em Sociedade e Cultura na Amazônia. Duas delas encontram-se atualmente no doutorado. Nos últimos anos, a maioria afirma ter intensificado nos últimos anos os laços entre ensino e pesquisa, tendo passado a participar com mais frequência - como ouvinte ou apresentador de trabalho - de eventos realizados em Parintins ou mesmo fora da sua cidade e do estado do Amazonas. De acordo com levantamento realizado na Plataforma Lattes, 43\% já publicaram artigos em periódicos indexados e praticamente todos tem algum tipo de publicação em anais ou outros suportes.

Quando questionados sobre a sua atuação profissional, pouco mais da metade diz ter trabalhado por contrato temporário antes de ingressar por concurso na docência do Ensino Básico. Desse conjunto, a mais antiga ingressou na rede estadual em 1990 e os mais recentes em 2012. Atualmente, todos atuam em turmas de História no Ensino Fundamental e no Ensino Médio.

Em relação às condições de trabalho nas escolas em que estão lotados (considerando que a maioria já passou por várias escolas) a estrutura física é referida como boa em $86 \%$ dos casos, da mesma forma que o material didático. Já o apoio pedagógico é avaliado para aproximadamente 50\% como regular e a remuneração divide as opiniões, sendo considerada péssima por $14,3 \%$, regular por $71,5 \%$ e boa por outros $14,3 \%$. Os dissensos sobre esse último tópico refletem em parte a luta dos professores por melhores salários e algum nível de satisfação (ainda que momentâneo) com as conquistas salariais granjeadas na última greve, que parou várias escolas de Parintins, 
em 2017.

Também nos interessou saber a quais materiais os professores recorrem com maior frequência para planejar suas aulas (?). Como havia possibilidade, nesse caso, de marcar várias opções, os resultados somam mais de 100\%. Em uma lista que contemplava: livros didáticos, livros paradidáticos, livros acadêmicos, internet (vários), vídeos/ músicas, revistas/textos avulsos ou outros, todos (100\%) assinalaram em suas respostas os livros didáticos e a internet; aproximadamente 30\% mencionara livros paradidáticos e vídeos/músicas; $14,3 \%$ marcaram ainda as opções revistas/ textos avulsos ou outros, mas sem indicar quais. Quando a questão foi levemente modificada para "a quais materiais você recorre com maior frequência durantes as suas aulas?" o cenário se modifica levemente. Livros didáticos são citados em cerca de $70 \%$ das respostas. Paradidáticos e acadêmicos são mencionados 42,9\% das vezes. E internet, vídeos/músicas e revistas/ textos em $28,6 \%$ das respostas. Uma professora assinalou apenas a resposta "outros" e indicou que prepara "slides com os temas a serem abordados", completando: "o livro didático apenas solicito para realização de exercícios".

\section{Breve avaliação das experiências ou perspectivas para os professores de História}

A parte final de nosso questionário cumpria o duplo objetivo de embasar a escrita desse texto e de servir como instrumento para uma leitura crítico-reflexiva sobre a oferta da especialização, com vistas inclusive em identificar e corrigir eventuais pontos críticos em uma eventual nova oferta desse curso de pós-graduação lato-sensu. Por isso pedimos que avaliassem os seguintes quesitos da Especialização em Metodologia do Ensino de História ofertada pela UEA/SEDUC-AM: disciplinas ofertadas, corpo docente, envolvimento coletivo e bibliografia discutida. Como se tratava de um questionário fechado, para cada questão foram oferecidas as alternativas: péssimo/a, ruim, regular, bom/boa ou ótimo/a. Foi com certa surpresa que recebemos uma avaliação totalmente positiva dos concluintes, que avaliaram todos os tópicos como ótimos.

Na sequência, construímos quatro questões nas quais havia espaço para comentários. A primeira delas indagava se "esta Especialização havia modificado o seu diálogo com os conhecimentos produzidos na Universidade" (?). As opções desta vez eram: não. nada, muito pouco, pouco, razoavelmente ou muito. E novamente, todos apontaram que "muito". Destacamos as respostas de duas professoras: "Sim, a especi- 
alização não só trouxe temáticas diferentes da graduação enriquecendo ainda mais nosso conhecimento como foi possível fazer uma releitura sobre o que já conhecíamos" e "Sim, essa Especialização enriqueceu meu vocabulário e conhecimentos sobre a História". Depois questionamos se acreditavam que "esta Especialização modificou seu diálogo com os seus alunos do Ensino Básico" (?). Diante das mesmas opções, todos assinalaram novamente "muito". Um professor justificou sua resposta dizendo que "todo aprendizado foi colocado em prática, melhorando não só as atividades como os diálogos com os alunos". Outro se viu, após a especialização, "mais aberto" às questões dos seus alunos.

Mesmo já conhecendo o desdobramento positivo da especialização sobre a carreira docente dos concluintes, achamos por bem perguntar a eles como avaliavam o impacto da especialização sobre as suas perspectivas de crescimento profissional. E como imaginávamos, todos responderam que as ressonâncias haviam sido muito grandes. Um justificou que "além de todo o aprendizado, foi uma realização pessoal que me [o] instigou a continuar progredindo em busca de qualificação profissional". A professora cuja formação inicial é em Filosofia acrescenta que ganhou "mais experiência e conhecimentos para trabalhar com a disciplina de História". A quarta e questão desse bloco (última do questionário), perguntava se, na opinião dos concluintes, "seria interessante replicar essa experiência para os demais professores de História da rede pública de ensino de Parintins? As respostas possíveis eram: não, sim ou sim, mas com alterações. Unanimemente todos indicaram que sim. Mencionamos novamente duas justificativas: "É de extrema importância que os professores tenham a oportunidade de se qualificarem, melhorando assim suas práticas em sala de aula" e "com certeza, essa especialização deve ser aplicada a todos os professores que trabalham com a disciplina de História".

\section{Considerações finais}

O que buscamos neste texto, sem muitas pretensões, foi compartilhar algumas de nossas experiências na Universidade que reforçam a importância da formação continuada para os professores de História que atuam na rede pública e da elaboração de parcerias entre a academia e as várias instâncias do Ensino Básico. Compreendemos que o ritmo acelerado das mudanças sociais tem impactado sobremaneira nos ambi- 
entes escolares, modificando de forma igualmente rápida as representações que os docentes fazem da História (como disciplina), dos atores institucionais que o circundam, da sala de aula e até mesmo das estratégias possíveis para mobilizar seus alunos para os conteúdos que contam do currículo (cf. Almeida Neto, 2011; Caimi, 2006).

Logo, ensinar História nunca foi tão desafiador quanto nesse contexto, no qual não há mais "um modelo ou luz a ser seguida", o que torna nossa a tarefa de fornecer aos estudantes um referência para que ele "situe a 'si' (identidade) e ao 'outro' (diferença) no tempo e no espaço, como forma de ampliação das possibilidades de participação política". Porém, conforme destaca Antonio Simplício de Almeida Neto (2011, p. 219), para que isso aconteça é preciso que os professores de História percebam-se como sujeitos fundamentais dessa transformação". Isso implica levar a sério as oportunidades de reinventar-se, aproveitar todas as ocasiões para rever práticas e representações passadistas (da História e da profissão docente) e encarar os novos desafios, que não cessam de brotar. Olhar criticamente para as expectativas e avaliações dessa Especialização na trajetória dos professores que a cursaram - hoje nossos parceiros de trabalho, nos ajuda a redimensionar a nossa atuação no presente e nossas perspectivas futuras, seja naquilo que propomos para as licenciaturas ou naquilo que imaginamos para a formação continuada.

\section{Referências}

ALMEIDA NETO, Antonio Simplício de. 2011. Representações utópicas no Ensino de História. São Paulo: UNIFESP.

ARAUJO, Valdei Lopes. 2012. A aula como desafio à experiência da história. In: GONÇALVES, Marcia de Almeida; MONTEIRO, Ana Maria; REZNIK, Luís; ROCHA, Helenice (org.). Qual o valor da história hoje?. Rio de Janeiro: FGV. pp. 66-77.

BRASIL. 1999. Parâmetros Curriculares Nacionais - História (Ensino Fundamental e Ensino Médio). Brasília: MEC.

. 2017. Base Nacional Comum Curricular. Brasília: MEC.

2018. Base Nacional Comum Curricular. Ensino Médio. Brasília: MEC.

CAIMI, Flávia Eloisa. 2006. Por que os alunos (não) aprendem História? Reflexões sobre ensino, aprendizagem e formação de professores de História. Tempo. Niterói: UFF, vol. 11, n. 21. pp. 17-32.

CAVALCANTE, Lucíola Inês Pessoa; WEIGEL, Valéria Augusta C. de M. 2002. Educação na Amazônia: oportunidades e desafios. In: MELLO, Alex Fiúza de (org.). O futuro da Amazônia: dilemas, oportunidades e desafios no limiar do século XXI. Belém: EDUFPA. 
pp. 71-86.

COSTA, Aryana Lima; OLIVEIRA, Margarida Maria Dias de. 2007. O Ensino de História como objeto de pesquisa no Brasil: no aniversário de 50 anos de uma área de pesquisa, notícias do que virá". Saeculum. João Pessoa: UFPB, n. 16, janeiro/junho. pp. 147160.

FONSECA, Selva Guimarães; GONÇALVES, Marco Antônio. 2010. OEnsino de História hoje: errâncias, conquistas e perdas. Revista Brasileira de História. São Paulo: ANPUH, v. 30, n. 60. pp. 13-33.

GALZERANI, Maria Carolina Bovério. 2013. Pesquisa em Ensino de História: saberes e poderes na contemporaneidade. In: SILVA, Marcos (org.). História: que ensino é esse? Campinas: Papirus. pp. 234-252.

GUSMÃO, Emery Marques. 2004. Memórias de quem ensina História. Cultura e identidade docente. São Paulo: UNESP.

HORN, Geraldo Balduíno; GERMINARI, Geyso Dongley. 2013. O Ensino de História e seu currículo. Teoria e método. $5^{\circ}$ ed. Petrópolis: Vozes.

MONTEIRO, Ana Maria. 2000. Ensino de História: das dificuldades e possibilidades de um fazer. In: DAVIES, Nicholas. Para além dos conteúdos no Ensino de História. Niterói: UFF. pp. 27-44.

; MAGALHÃES, Marcelo de Souza; GASPARELLO, Arlette Medeiros (org.). 2007.

Ensino de História: sujeitos, saberes e práticas. Rio de Janeiro: Mauad X: FAPERJ.

PINSK, Carla Bassanezi (org.). 2013. Novos temas nas aulas de História. $2^{\circ}$ ed. São Paulo: Contexto.

SILVA, Caio Henrique Faustino da Silva; ZOGAHIB, André Luis Nunes. 2015. PROFORMAR: uma experiência amazônica em política pública educacional. In: Revista Intersaberes. Curitiba: UNINTER, v. 10, n. 19, janeiro-abril. pp. 110-125.

SILVA, Marcos; GUIMARÃES, Selva. 2012. Ensinar História no século XXI: em busca do tempo entendido. 4 o ed. Campinas: Papirus.

UNIVERSIDADE DO ESTADO DO AMAZONAS. 2014. Projeto do Curso de Especialização em Metodologia do Ensino de História. Manaus: UEA.

Artigo recebido em outubro de 2018 e aceito em novembro de 2018. 